Max-Planck-Institut für demografische Forschung

Max Planck Institute for Demographic Research

Konrad-Zuse-Strasse 1 - D-18057 Rostock · GERMANY

Tel +49 (0) 3812081 - 0; Fax +49 (0) 3812081 - 202;

http://www.demogr.mpg.de

MPIDR WORKING PAPER WP 2005-027

SEPTEMBER 2005

\title{
Social differentials in speed-premium effects in childbearing in Sweden
}

\author{
Gunnar Andersson (andersson@ demogr.mpg.de) \\ Jan M. Hoem (hoem@demogr.mpg.de) \\ Ann-Zofie Duvander
}

This working paper has been approved for release by: Gerda Ruth Neyer (neyer@ demogr.mpg.de) Deputy Head of the Laboratory of Contemporary European Fertility and Family Dynamics.

(C) Copyright is held by the authors.

Working papers of the Max Planck Institute for Demographic Research receive only limited review. Views or opinions expressed in working papers are attributable to the authors and do not necessarily reflect those of the Institute. 


\title{
Social differentials in speed-premium effects in childbearing in Sweden
}

\author{
Gunnar Andersson, Jan M. Hoem, and Ann-Zofie Duvander
}

\begin{abstract}
In Sweden, parents receive a parental-leave allowance of a high percentage of their pre-birth salary for about a year in connection with any birth. (The percentage has changed over time, as has the period for which it is paid. For a birth that appears in 2005 , parents get $80 \%$ of the salary for thirteen months.) If they space their births sufficiently closely, they avoid a reduction in the allowance caused by any reduced income earned between the births. The gain is popularly called a "speed premium". After some precursors in legal practice, this rule was made statutory in 1980 and the "eligibility interval" was then set to 24 months. In 1986, it was extended to more attainable thirty months. In previous work we have displayed a corresponding speedup effect in childbearing for Swedish-born women. This change in behavior is of general interest since it is clear evidence of a causal effect of a policy change on childbearing behavior. In the present paper, we study how this change in behavior was adopted in different social strata of the Swedish population. We examine whether the speed-up of childbearing differed by educational attainment and by country of origin, to see whether some social groups reacted faster or more strongly to the policy change than others. We cannot find any important difference in the reaction to the introduction of the "speed premium" between educational groups of Swedish-born parents. Similarly, we find no important difference in the mode of reaction between Swedish-born women and Nordic immigrants to the country. By contrast, immigrants from non-Nordic countries hardly seem to have reacted to the "speed premium".
\end{abstract}

Paper prepared for the workshop on "Life history events analysis in epidemiology and fertility studies", in honor of Niels Keiding, Bordeaux, 15-16 September 2005. 


\section{Introduction}

In Sweden, parents have long been entitled to paid parental leave in connection with any birth. ${ }^{1}$ The benefit received during the leave is closely connected to previous labor-market activity: Leave-taking mothers and fathers receive an allowance of a high percentage (currently $80 \%$ ) of their pre-birth salary up to a relatively high ceiling. ${ }^{2}$ All parents who live permanently in Sweden are entitled to such a benefit. If they space their births sufficiently closely, they are guaranteed to avoid any reduction in allowance from one parental leave to another. This guarantee is popularly called the "speed premium". ${ }^{3}$ It consists in having the benefit connected to any birth after the first be the same as for the preceding child if the earlier benefit level was above what the parents would otherwise gain a right to during the inter-birth interval. This constitutes a premium if the leave-taking parent earned a lower income (for example, because of part-time work, which is common among new mothers) or had no income in the period between the two births. After some precursors in legal practice, this rule was made statutory in 1980 and the maximum interval between the births that makes the parent eligible for the "speed premium" was then set to 24 months. In 1986, it was extended to the more attainable thirty months. ${ }^{4}$ (See Hoem, 1990: 744-745, for more information about the "speed premium".) In previous work we have displayed a corresponding speed-up effect in childbearing (Hoem, 1990, 1993; Andersson, 1999); the most convincing demonstration that this speed-up indeed was caused by the policy change is given by Andersson $(2002,2004 a)$. One reason for

\footnotetext{
${ }^{1}$ For an international overview of parental-leave policies and their consequences, see Moss and Deven (1999), Kamerman (2000), Ferrarini (2003), Neyer (2003); for an overview of Swedish parentalleave policies, see Haas and Hwang (1999), Duvander, Ferrarini, and Thalberg (2005).

${ }^{2}$ The number of months of entitlement has varied over the years; in most of the 1980s the entitlement was for nine months, and in the 1990s it mostly was for twelve months. This covers the two decades of our empirical investigation. Since 2002 the entitlement has been for thirteen months. The entitlement can be prolonged by being taken up part-time and it can be taken out in installments until the child is eight years old. The percentage of income compensation has also changed over time. Between 1974 and 1994 it was set at 90\%. During the second half of the 1990s it was reduced to $80 \%$ and for a brief period to $75 \%$. Later it has been raised again to $80 \%$ of the previous salary. In addition, there is an entitlement to a subsequent parental leave at a much lower flat rate; since 1980 this additional entitlement is for three (extra) months. For an account of the history of family policies in Sweden through 1996, consult Hoem and Hoem (1996).

${ }^{3}$ The term refers to sales tricks used by mail-order firms, particularly in books sales.

${ }^{4}$ One motive for the introduction of the "speed premium" was to protect mothers from losing too much money from the common practice of reducing their work hours when they had small children. Today this motive has less political support. A recent public commission has even recommended that the "speed premium" be abolished on the ground that it encourages mothers to work part time rather than full time (SOU, 2004).
} 
the possibility of such a strong effect on childbearing dynamics is the common practice of Swedish mothers to stay in the labor force after childbearing but to reduce their working hours. More than 40 percent of employed mothers with children under 7 work part-time (Statistics Sweden, 2001).

In the present paper we use Swedish register data to study whether we can find any differentials in speed-premium usage among parents living in Sweden in the 1980s and 1990s. We study changes in fertility patterns ever since the "speed premium" was made statutory in 1980 and in particular gauge effects of the extension of the statutory "eligibility interval" in 1986. We focus on differences in fertility adaptation by different social groups. First, we demonstrate to what extent changes in birth-spacing behavior differ between Swedish- and foreign-born women. Pursuing the issue of societal segmentation a step further, we also address the question whether Swedish-born parents at the various educational levels picked up the advantages of the "speed premium" with different rapidity and possibly at different strengths. This procedure may allow us to detect barriers in how social learning and social influence can affect the diffusion of fertility change in Sweden (cf. Bongaarts and Watkins, 1996; Montgomery and Casterline, 1996; Kohler, Billari, and Ortega, 2002). A differential by educational attainment could be interpreted as a shortcoming of the public information system. Differences in fertility adaptation may also stem from differences in the labor-market attachment of different population subgroups and related differences in the incentives to space children closely. They may also be due to differences in the willingness to adapt fertility behavior to policy changes.

\section{Data and procedure}

Studies of demographic behavior in Sweden have the advantage of access to high-quality individual-level data from a population register that covers everyone who contributed to the population census of 1960, or who has been born in the country subsequently, or who has entered the system as an immigrant since that census. The register contains records of all demographic events like birth, death, marriage formation, divorce, international migration, and even change of address in Sweden. For each vital event there is a record of the date at which it took place, with the limitation that we "only" have had access to an address record at the end of each calendar year. 
Each birth record contains the identification number of the child's mother and father. From the demographic records and from the address records one can reconstruct which children are born in consensual or marital unions. From subsequent address changes one can reconstruct which unions were dissolved later and the year of disruption.

A separate educational register contains individual-level records of educational attainment at the end of each year, starting in 1980. We have had an extract made through 1998 and can therefore use educational attainment as a factor influencing childbearing in 1981 through 1999 for each individual born in Sweden who lived in the country throughout that period, until first emigration for those who outmigrated at least once, and until death for those who died during the period of observation. Since foreign education is not recorded, histories of educational attainment for immigrants are too spotty to be of much use for our purposes. Since our educational data refer to the period after 1980, we just miss the possibility of comparing childbearing behavior before the introduction of the statutory right to a "speed premium" in 1980 with what happened thereafter. We therefore concentrate mostly on the effect of the extension of the eligibility interval from 24 to 30 months in 1986 . This is the part of the policy implementation that we know affected childbearing behavior most strongly.

For all Swedish-born couples recorded to have a common child while living together in Sweden, we have had an extract made and have produced a couplespecific life history containing the date of birth of the first child and of any second and third child which they had together. We use an observational period from the beginning of 1981 to the end of 1999 and left-censor each record at the start of 1981. A record is right-censored at any multiple birth (twins, triplets, or whatever), at the end of the year when a member of any couple moves out of the country, when the couple splits up (if ever), when the man or the woman dies, or at the end of 1999. ${ }^{5}$ Our events are second and third births. A multiple birth is counted as a birth event of the relevant order, but observation is stopped at that birth. All observation is stopped at any third birth. For couples where both partners were born in Sweden, our extract of the

\footnotetext{
${ }^{5}$ Life histories were actually eliminated (rather than right-censored) if they contained a record of a multiple birth or a third birth before the beginning of 1981, as were records where before that date the parents had split up or moved out of Sweden or one of them had died. A life history would also be eliminated if the woman had a child before the formation of the index union.
} 
couple's life history also contained their individual histories of educational attainment in 1981-1999. For our purposes, educational attainment has been coded as education at the primary, secondary, or tertiary level only; other details have been suppressed here. ${ }^{6}$ For further examples of studies on the childbearing dynamics of the Swedish parents in our data, see Duvander and Andersson (2003, 2005), and Andersson, Duvander, and Hank (2004, 2005).

For the comparison of immigrants with the Swedish-born population we have used a simpler procedure. First of all, the life histories are only constructed for women (i.e., not for couples), and we have left out their recorded educational histories, such as they are. Information on immigrant mothers is left-censored at the first immigration to Sweden. We make a distinction between (female) immigrants from the other Nordic countries (Iceland, Norway, Denmark, and Finland) and those who originate from non-Nordic countries, and analyze these two groups separately. The first group has a cultural background that is very similar to that of the Swedish-born population. It provides around 3-4 percent of the records in our data. The latter group provides close to 10 percent of our study records. It is very heterogeneous and comprises women from practically all corners of the world without any dominance of any particular nationality. Concentrating on women saves us from a number of headaches, like having to keep track of unions where the man and the woman come from different countries. For further information on patterns in childbearing of immigrant women in Sweden, see Andersson (2004b). Andersson and Scott (2005) have studied additional aspects of the fertility behavior of immigrants in Sweden, in particular how their childbearing is related to their labor-market attachment.

\section{Empirical results}

\subsection{Swedish-born women vs. immigrants}

For our study of second-birth behavior among Swedish-born and immigrant women, we have used a hazard-regression analysis with an intensity of the form $h_{j}(t)=a_{j, y(t)} d_{j, i(t), k(t)}$, where $j$ is an index for our three groups of women (the Swedish born, Nordic immigrants, and non-Nordic immigrants, respectively). Our process time

\footnotetext{
${ }^{6}$ For the general importance of such details, see Hoem, Neyer, and Andersson (2005).
} 
$t$ is the age of the first child, or more correctly, the duration since the first birth, computed in months and grouped in a manner intended to pick up the effect of the eligibility intervals for the "speed premium". 7 The piecewise-constant baseline intensity for women in group $j$ in calendar year $k(t)$ is $d_{j, i(t), k(t)}$, where $i(t)$ is the number of the duration interval that covers process time $t$. Our $k(t)$ represents the calendar year at process time $t$; we use single calendar-year intervals. The factor $a_{j y}$ is a parameter representing a multiplicative effect on the intensity of having a child in age group $y$; $y(t)$ is the current woman's age group at process time $t$. We include this factor to control for any compositional effect of age. Since this factor does not otherwise interfere with our study of speed-premium effects, we do not report any empirical results about it here. ${ }^{8}$ Note that (as the notation indicates) the mother's age appears as a time-varying covariate, and so does calendar time. The only fixed covariate is the population group indicator $j$. For third births we use an intensity specification of the same type, except that process time $t$ is the duration since the second birth.

Figures $1 \mathrm{a}$ and $1 \mathrm{~b}$ contain plots of estimated baseline intensities $d_{j i k}$ for second-birth risks of Swedish-born and non-Nordic immigrant mothers, respectively. They serve the purpose of depicting patterns in spacing of second births and how these patterns changed with the introduction of the "speed premium" during the 1980s for the main population of Swedes and for the subgroup where we found the most deviating development in patterns of that kind. The changes in second-birth dynamics during the 1980s are summarized in Figure 2a. It gives the relative change in birth risks between 1990 and 1981 at the different durations since the previous birth for the three subgroups of women we study. A corresponding summary of changes in thirdbirth dynamics during the 1980s is provided in Figure 2b. Several comments are in order.

\footnotetext{
${ }^{7}$ Our age groups are $0-11$ months of age (called "age 0 " in the diagrams that follow), 12-17 months (called "age 1 year"), 18-23 months (called "age 1.5 years"), 24-29 months (called "age 2 years"), 30-35 months ("2.5 years"), 36-47 months ("3 years"), and correspondingly for groups "4 years", "5 years", "6-7 years", and "8-9 years". Note that the speed-premium eligibility intervals ended after "age 1.5" between 1980 and 1985, and after "age 2" from 1986 onwards.

${ }^{8}$ The intensity specification that we have indicated is equivalent to a study of each of our three groups of women separately. Experiments suggest that it would not have mattered if we had used the same age parameter for all three groups, i.e., if we had behaved as if $a_{j y}$ were independent of $j$.
} 


\subsubsection{Second births}

In Figure 1a there is an obvious jump in the second-birth risk between 1986 and 1987 for the key group 24-29 months of age of the first child, and further jumps in the years that followed. We take this as a reaction among the Swedish-born to the extension of the speed-premium eligibility interval from 24 to 30 months in 1986. The result of the cumulative changes that took place in second-birth risks during the 1980s is that they had increased disproportionably at all durations shorter than 30 months since the first birth (Figure 2a).

For the Nordic immigrants, we find a fairly similar change in second-birth dynamics during the 1980s (Figure 2a). Levels in second-birth risks are similar to those of the Swedish-born population (not shown); the limited size of the population subgroup makes year to year changes affected by random variation. A closer inspection of such changes (not shown) suggests that the Nordic immigrants had a tardier and somewhat less strong reaction to the changes in speed-premium regulations than Swedish-born women did. Nevertheless, Figure 2a shows that cumulatively over the years, there is considerable growth in the risk over time at the key duration 24-29 months, both for the Swedish-born and for Nordic immigrants; in fact there is considerable growth even at the just-earlier duration (18-23 months of age) at which the "speed premium" was in force throughout our two decades of observation.

Finally, the non-Nordic immigrants (Figure 1b) have much lower second-birth risks than the Swedish-born. We cannot see anything that looks like a reaction to the speed-premium benefits at parity 1 for the non-Nordic immigrants (Figure 1b and 2a).

\subsubsection{Third births}

In Figure $2 b$ we summarize the changes that occurred in third-birth risks during the 1980s for the same population subgroups. There is an obvious increase in the third-birth risk of Swedish-born and Nordic immigrant mothers when the second child is less than 30 months old. Evidently, Nordic two-child parents reacted to the introduction and extension of the "speed premium" by speeding up their childbearing 9 . In

\footnotetext{
${ }^{9}$ A close inspection of yearly changes in duration-specific third-birth dynamics reveals that they are well synchronized with the policy change in 1986 and with how it applied to the various birth intervals. Patterns for Nordic immigrants are affected by much random variation.
} 
contrast, we cannot see anything that looks like a reaction to the speed-premium benefits at parity 2 for the non-Nordic immigrants.

We now turn to educational differentials for the Swedish-born.

\subsection{Educational differentials between parents born in Sweden}

For our study of second-birth behavior of couples where both partners were born in Sweden, we have used a hazard-regression analysis with an intensity that in its simplest version has the multiplicative form

$$
h(t)=a_{x(t)}^{M} a_{y(t)}^{W} b_{m(t)}^{M} b_{w(t)}^{W} d_{i(t), k(t)} .
$$

As before, process time $t$ is the duration since the first birth. The piecewiseconstant baseline intensity is $d_{i(t), k(t)}$, where again $i(t)$ is the number of the duration interval that covers process time $t$ and $k(t)$ represents the calendar year at process time $t$.

In the intensity formula, $x(t)$ and $y(t)$ are the man's and the woman's age group at process time $t$, respectively; $a_{x}^{M}$ is a multiplicative parameter representing the effect (on the intensity) of having a man in age group $x$, and $a_{y}^{W}$ is the corresponding effect of the woman being in age group $y$. These two ages appear only as control variables and are not documented further here.

Similarly, $m(t)$ and $w(t)$ are the man's and the woman's educational attainment at process time $t$, respectively; $b_{m}^{M}$ and $b_{w}^{W}$ are the effects of having a man and a woman with attainments at levels $m$ and $w$, respectively. Estimates are contained in Table 1 along with corresponding estimates for third-birth risks. (For third births we use an intensity specification of the same type, except that process time $t$ is the duration since the second birth.) Note that (as the notation indicates) the parents' ages and educational attainments appear as time-varying covariates, as does calendar time. There are no fixed covariates in this case.

As usual, simultaneous effects of two covariates can be represented in less elementary intensity specifications as interactions. For instance, if the educational attainments of the man and the woman interact, we replace the product $b_{x(t)}^{M} b_{y(t)}^{W}$ by some 
factor $f_{x(x), y(t)}^{M W}$ that represents their simultaneous effect on the childbearing intensity. This could be useful if there were some synergy between his and her educational attainment. Fortunately and interestingly, it turns out that this will not be necessary with our data, neither for second nor for third births. ${ }^{10}$ In the present case, we therefore get the result that a couple where both partners have attained a tertiary education, has a second-birth risk estimated at 1.77 (i.e., very close to the $1.44 * 1.24=1.79$ that we can compute from Table 1) times the corresponding risk for couples where both partners have no more than a primary education, ceteris paribus, and we get corresponding relative risks for other pair combinations of educational attainment (and for third births). The structure of the estimates for these parameters is not of prime interest in our investigation, so we confine our reflections to the following few comments:

(i) For both second and third births, the more highly educated have much the higher birth risks, all else considered, both for men and women. For women this is a rather common finding in investigations of educational gradients in second- and thirdbirth risks based on individual-level data, and it is directly contradictory to the usual predictions from economic theory. People have spent much energy explaining it, or explaining it away. Among procedures applied are sophisticated uses of the covariate "age at first birth" (see in particular B. Hoem, 1996) and arguments involving differential childbearing selectivity at different educational attainments (see, e.g., Hoem, Prskawetz, and Neyer, 2001, and their precursors; see also Kravdal, 2001, and Kreyenfeld, 2002). Pursuing this issue would lead us down a side-track for our investigation, however, so we let the question rest.

(ii) In their studies of second and third births in Austria, Prskawetz and Zagaglia (2005) and Hoem, Prskawetz and Neyer (2001) found that the effect of a woman's educational attainment disappeared when they added her husband's attainment among the active covariates. Kreyenfeld (2002) found the same for second births in Germany. Our finding shows that this is not the case in Sweden. We see that as a reflection of differences in family culture.

\footnotetext{
${ }^{10}$ Our maximum-likelihood estimates of $\left\{f_{x y}^{M W}\right\}$ are not significantly different from estimates of the products $\left\{b_{x}^{M} b_{y}^{W}\right\}$ and the pattern of the former is not different from the pattern of the latter in any interesting way.
} 
(iii) Our present findings show that a Swedish woman's educational level has a discernable influence on her childbearing at parities 1 and 2, and so does her man's educational level. Not taking educational level into account in our Section 3.1 is, therefore, essentially a case of model misspecification. In principle, some of the effects we found in our previous subsection could be a result of differential group composition. Intuition suggests that such compositional effects should not be able to mask the structural differences that we focus on here, however. In other words, the model misspecification is probably harmless. ${ }^{11}$

Returning now to our main line of argument, we note that the main thrust of our investigation is to see what kind of effect we can discover of the reform of the speed-premium regulations in 1986. For this purpose we concentrate on the three-way interaction between process time $t$, calendar time $k(t)$, and the woman's educational attainment $w(t)$. This consists in replacing the product $b_{w(t)}^{W} d_{i(t), k(t)}$ by some factor, say $g_{w(t), i(t), k(t)}$, in the intensity formula. We present various features of the maximumlikelihood estimates of the parameters $\left\{g_{w i k}\right\}$ and show how they relate to each other.

Figure 3a provides a summary of how the profiles in second-birth risks by duration since first birth changed during the 1980s for mothers with a primary, secondary, and tertiary education, respectively. Figure $3 b$ gives the corresponding information for third-birth risks. This is achieved by plotting the second- and third-birth risks in 1990 relative to those in 1981, for the various age groups of the last previous child, separately for each educational level, just as we did in Figure 2 for each group of countries of origin. In our view, there are no discernable differentials by educational level in the comparison between the risks for these particular years, nor have we found important differentials when we compare other pairs of suitable years. For all educational groups of mothers there is a much stronger increase in childbearing at durations shorter than 30 months since last previous birth than at longer durations.

Remember that the reform in 1986 consisted in an extension of the eligibility interval from 24 to 29 months. We would expect this to result in increased fertility at age 2.0 of the previous child from 1987 and onwards. This is precisely what we see in Figure $4 \mathrm{a}$, where we plot second-birth risks against calendar year for mothers with a

\footnotetext{
${ }^{11}$ For a discussion of harmless model misspecification of this kind, see Hoem (1995).
} 
first child in the critical age group of 24-29 months as compared to those with a first child in the following age group (30-35 months). To neutralize the differences in risk level at the various educational attainments, we have divided each set of risks by the value for 1981 . We see the curves for the former but not for the latter age group take a strong leap upward after 1986, as we would expect if there is an effect of the extension of the eligibility interval for the "speed premium". Figure $4 \mathrm{~b}$ demonstrates the same effect if education is measured by the characteristics of the father instead. (Patterns for third births are influenced by stronger general period fluctuations and are not displayed here.) We feel vindicated in our claim that there is no important educational differential, neither for men nor for women, in the effect of the speed-premium extension in 1986, and we have not found any subsequent differential in later years either. ${ }^{12}$ As concerns the durability of the policy effect we note that the differentials in fertility development between mothers at the two durations since last previous birth remained intact also when fertility declined during the 1990s (Figure 4). The "speed premium" appears to have had a lasting impact on the manner Swedish parents space their births.

\section{Discussion}

In our study, we have found no important educational differentials in the reaction to the "speed premium" by women and men born in Sweden. Parents at all educational levels adjusted their childbearing behavior to produce much shorter birth intervals than they did before the premium was introduced. Interestingly, not only the magnitude in the change in behavior but also the rapidity in the adaptation to the new policy was very much the same across educational groups. The change did not appear in a single group and then spread to other educational groups in Swedish society. In all educational categories, we observe an immediate response to the extension of the eligibility interval in 1986. This similarity in behavior fits rather well with the stereotype of Swedish society as having a large degree of homogeneity in terms of social dynamics.

\footnotetext{
${ }^{12}$ The somewhat slower increase in second-birth risks of mothers at the duration 24-29 months with a primary education as compared to mothers with a secondary or tertiary education can be related to the slower increase in second-birth risks in general among the low educated.
} 
In addition, we have found the same patterns of decreasing intervals between the three first births among female immigrants from other Nordic countries as for Swedish-born women. This suggests that Nordic immigrants both learned how to use the system on a par with the Swedish-born and perceived the same gains from using the "speed premium". By contrast, immigrants from non-Nordic countries hardly seem to have reacted to the "speed premium". We conjecture that either the knowledge about this feature of Swedish public policies did not spread to such women as effectively, or else they were less willing to change their behavior in response to policies introduced by Swedish authorities, or they were less strongly connected to the labor market before their first birth and therefore would not earn as much of an economic premium by speeding up their childbearing. (Remember that maternity benefits are closely related to a woman's own pre-birth earnings.) Alternatively, they could have been less likely to reduce their working hours after childbirth, which also would reduce their perceived benefit from using the "speed premium". In all cases, we interpret the finding as an indicator of some segmentation in Swedish society.

It would have been interesting to see whatever educational differentials we could find in the reaction to the speed-premium extension among immigrants as well, but due to data limitations, we cannot account reliably for educational attainment in our analysis of the immigrants. In addition, it is important to study whether nonNordic immigrant mothers who were well established in the labor market before giving birth also failed to respond to the new policy, and whether we can discern any behavioral differentials among the various (small) country groups of non-Nordic immigrants, or whether the existence of a Swedish-born partner affects behavior, but these topics must be left for future research.

\section{Acknowledgements}

Jonathan MacGill organized our extract of raw data and produced our records for individual couples. We thank Gerda Neyer for taking much time to discuss our findings with us and Dorothea Rieck and Anne Hornung for assistance in the production of our diagrams under instruction by Silvia Leek. 


\section{References}

Andersson, G., 1999. Childbearing trends in Sweden 1961-1997. European Journal of Population 15: 1-24.

Andersson, G., 2002. Fertility developments in Norway and Sweden since the early 1960s. Demographic Research 6 (4): 67-86. Available at http://www.demographic-research.org/Volumes/Vol6/4.

Andersson, G., 2004a. Childbearing developments in Denmark, Norway, and Sweden from the 1970s to the 1990s: A comparison. Demographic Research Special Collection 3 (7): 155-176. Available at http://www.demographic-research.org.

Andersson, G., 2004b. Childbearing after migration: Fertility patterns of foreign-born women in Sweden. International Migration Review 38(2): 747-775.

Andersson, G., A.-Z. Duvander, and K. Hank, 2004. Do child-care characteristics influence continued child bearing in Sweden? An investigation of the quantity, quality, and price dimension. Journal of European Social Policy 14(4): 407418.

Andersson, G., A.-Z. Duvander, and K. Hank, 2005. Erwerbsstatus und Familienentwicklung in Schweden aus paarbezogener Perspektive. In: Tölke, A., and Hank, K., eds, Männer - Das ,vernachlässigte' Geschlecht in der Familienforschung [Sonderheft 4 der Zeitschrift für Familienforschung]: 220234. Wiesbaden: VS Verlag für Sozialwissenschaften.

Andersson, G., and K. Scott, 2005. Labour-market status and first-time parenthood: The experience of immigrant women in Sweden, 1981-97. Population Studies 59(1): 21-38.

Bongaarts, J., and S. Watkins, 1996. Social interactions and contemporary fertility transitions. Population and Development Review 22 (Supplement): 639-682.

Duvander, A.-Z. and G. Andersson. 2003. När har vi råd att skaffa fler barn? En studie om hur inkomst påverkar fortsatt barnafödande. RFV analyserar 2003:8. Stockholm: National Social Insurance Board.

Duvander, A.-Z. and G. Andersson. 2005. Gender equality and fertility in Sweden: A study on the impact of the father's uptake of parental leave on continued childbearing. MPIDR Working Paper, WP 2005-013. Rostock: Max Planck Institute for Demographic Research. 
Duvander, A.-Z., T. Ferrarini, and S. Thalberg, 2005. Swedish parental leave and gender equality. Achievements and reform challenges in a European perspective. Arbetsrapport 2005:11. Stockholm: Institutet för framtidsstudier.

Ferrarini, T. 2003. Parental Leave Institutions in Eighteen Post-war Welfare States. Swedish Institute for Social Research, Dissertation Series. Stockholm: Stockholm University.

Haas, L. and P. Hwang. 1999. Parental leave in Sweden. In Parental Leave: Progress or Pitfall?, edited by P. Moss and F. Deven, pp 45-68. NIDI/CBGS Publications, Vol. 35. The Hague/Brussels: NIDI/CBGS.

Hoem, B., 1996. The social meaning of the age at second birth for third-birth fertility: A methodological note on the need to sometimes respecify an intermediate variable. Yearbook of Population Research in Finland 33, 333-339.

Hoem, B. and J. Hoem (1996). Sweden's family policies and roller-coaster fertility. Journal of Population Problems 52 (3-4): 1-22.

Hoem, J., 1990. Social policy and recent fertility change in Sweden. Population and Development Review 16: 735-748.

Hoem, J., 1993. Public policy as the fuel of fertility: effects of a policy reform on the pace of childbearing in Sweden in the 1980s. Acta Sociologica 36: 19-31.

Hoem, J., 1995. Harmless omission in the standardization of demographic rates. European Journal of Population 11: 313-322.

Hoem, J., G. Neyer, and G. Andersson, 2005. Childlessness and educational attainment among Swedish women born in 1955-59. MPIDR Working Paper, WP 2005-014. Rostock: Max Planck Institute for Demographic Research.

Hoem, J., A. Prskawetz, and G. Neyer, 2001. Autonomy or conservative adjustment? The effect of public policies and educational attainment on third births in Austria, 1975-96. Population Studies 55: 249-261.

Kamerman, S. 2000. Parental leave policies: An essential ingredient in early childhood education and care policies. Social Policy Report 14: 3-15.

Kohler, H.-P., F. Billari, and J.A. Ortega, 2002. Towards a theory of lowest-low fertility. Population and Development Review 28: 641-680.

Kravdal, Ø., 2001. The high fertility of college educated women in Norway: An artefact of the separate modelling of each parity transition. Demographic Research 5: 187-216. Available http://www.demographic-research.org/Volumes/Vol5/6. 
Kreyenfeld, M., 2002. Time-squeeze, partner effect or self-selection? An investigation into the positive effect of women's education on second birth risks in West Germany. Demographic Research 7: 15-47. Available http://www.demographicresearch.org/Volumes/vol7/2.

Montgomery, M., and J. Casterline, 1996. Social learning, social influence, and new models of fertility. Population and Development Review 22 (Supplement): 151175.

Moss, P. and F. Deven. 1999. Parental Leave: Progress or Pitfall? NIDI/CBGS Publications, Vol. 35. The Hague/Brussels: NIDI/CBGS.

Neyer, G., 2003. Family policies and low fertility in Western Europe. Journal of Population and Social Security (Population) 1 (Supplement): 46-93 (in Japanese). Also available as MPIDR Working Paper, WP 2003-021. Rostock: Max Planck Institute for Demographic Research.

Prskawetz, A., and B. Zagaglia, 2005. Second births in Austria. Vienna Yearbook of Population Research, forthcoming.

Statistics Sweden, 2001. Arbetskraftundersökningen. Grundtabeller. Fjärde kvartalet 2000. Stockholm: Statistics Sweden.

SOU, 2004. Föräldraförsäkringsutredningen. Direktiv 2004:44. Stockholm: Statens Offentliga Utredningar. 
Table 1: Relative risk of second or third birth, by parent's educational attainment. Swedish-born couples with one or two common children. Standardized for age of mother, age of father, calendar year, and duration since last previous birth

One-child parents

Two-child parents

\begin{tabular}{lcc}
\hline Education of mother & 1 & 1 \\
Primary & 1.16 & 1.06 \\
Secondary & 1.44 & 1.59 \\
Tertiary & & \\
Education of father & 1 & 1 \\
Primary & 1.05 & 0.98 \\
Secondary & 1.24 & 1.23 \\
Tertiary & & \\
\hline
\end{tabular}


Figure 1: Standardized second-birth rates, by duration since first birth. Swedish-born and non-Nordic immigrant mothers. Selected calendar years

a) Swedish-born women

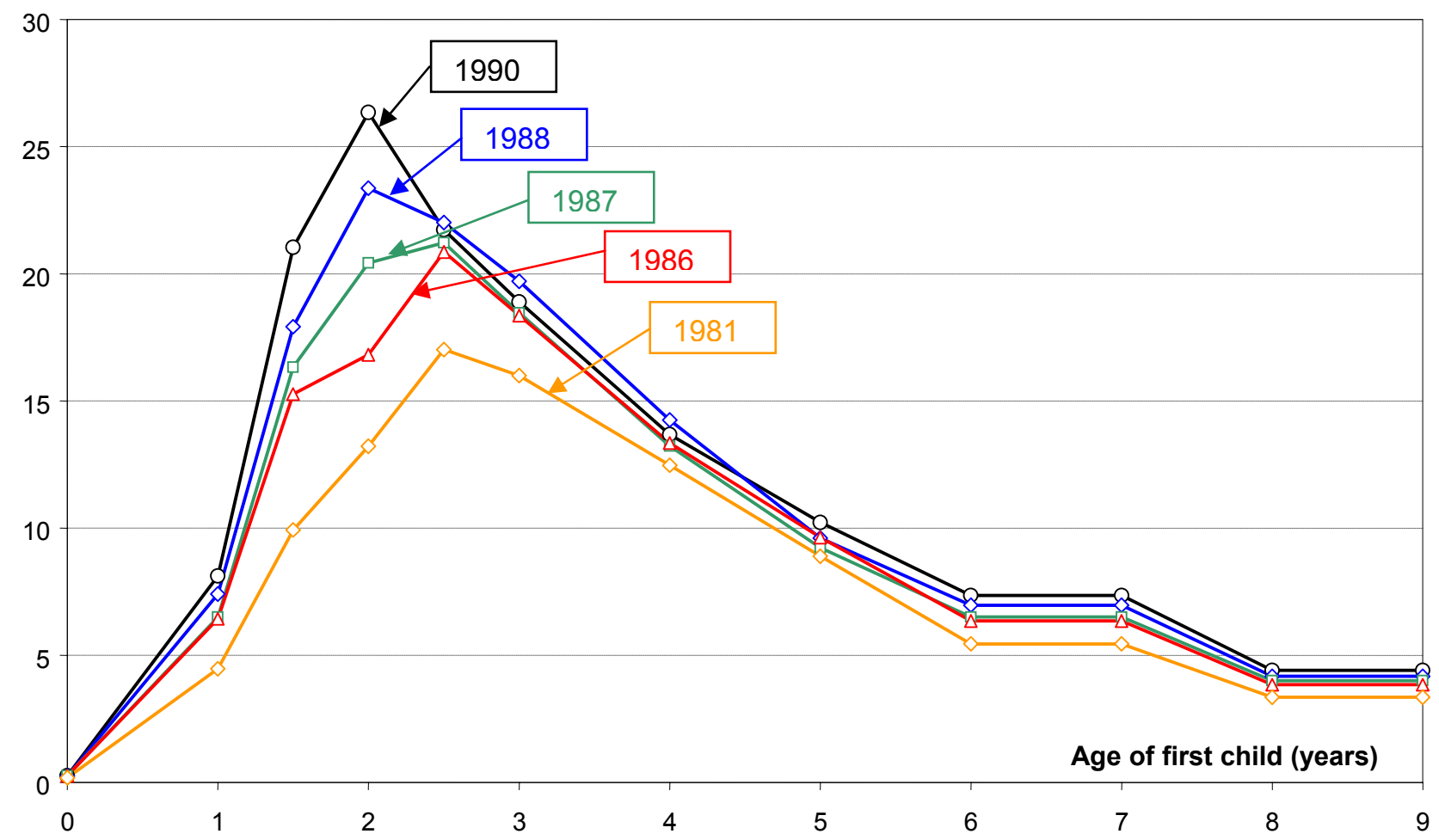

b) Non-Nordic immigrant women

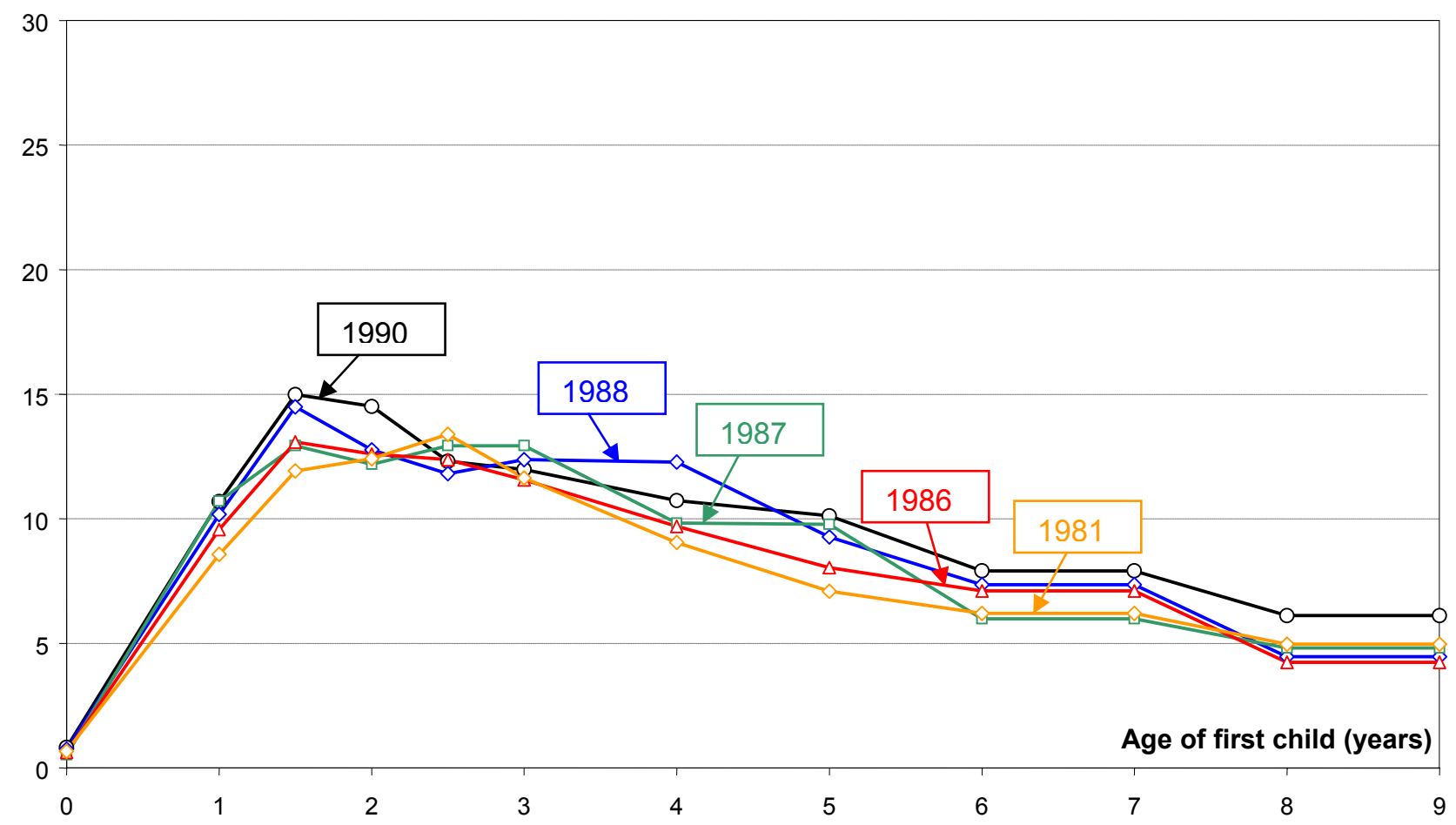


Figure 2: Second- and third-birth risks in 1990 relative to 1981, by duration since last previous birth. Mothers by countries of origin

a) Second-birth risks

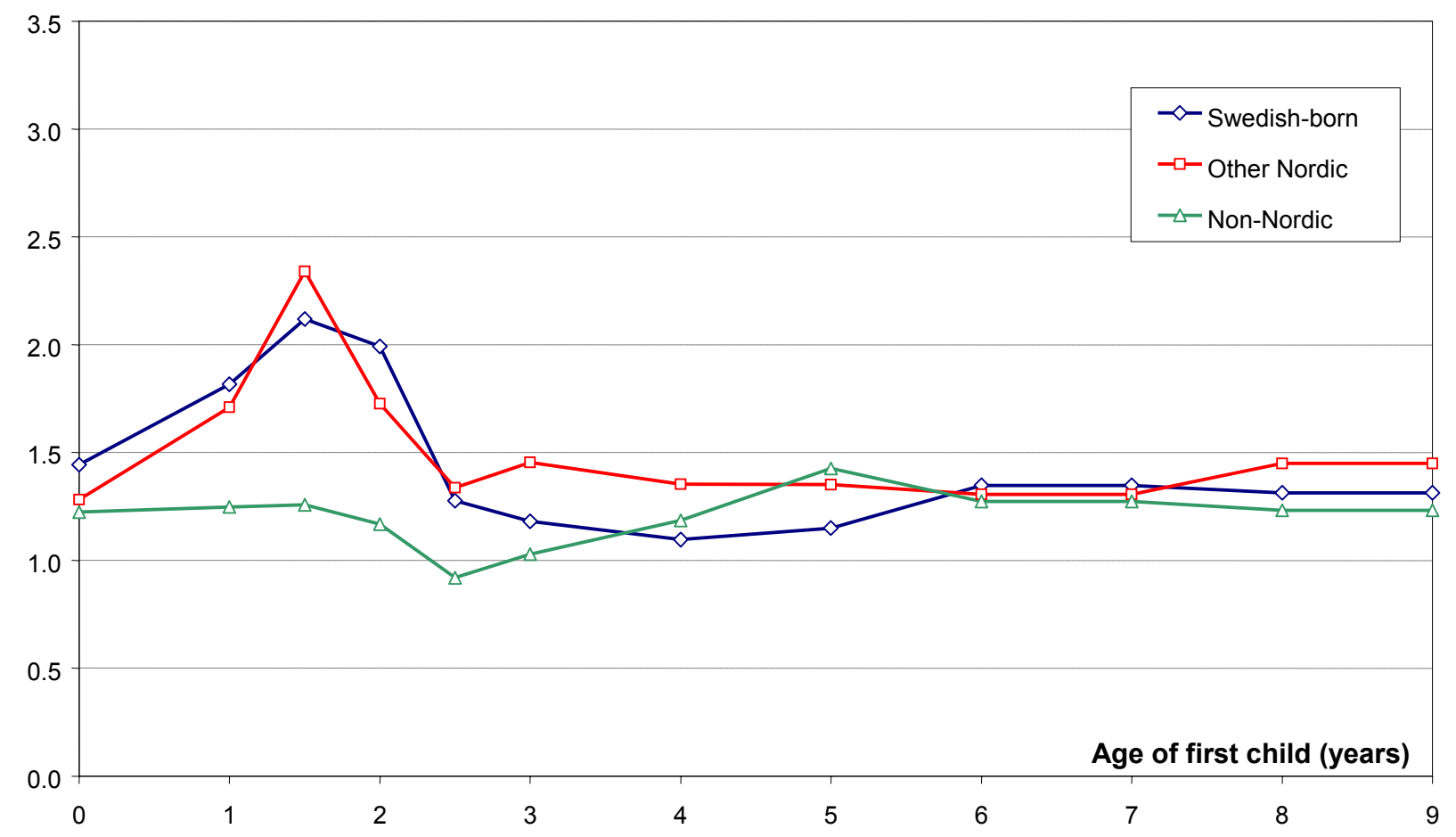

b) Third-birth risks

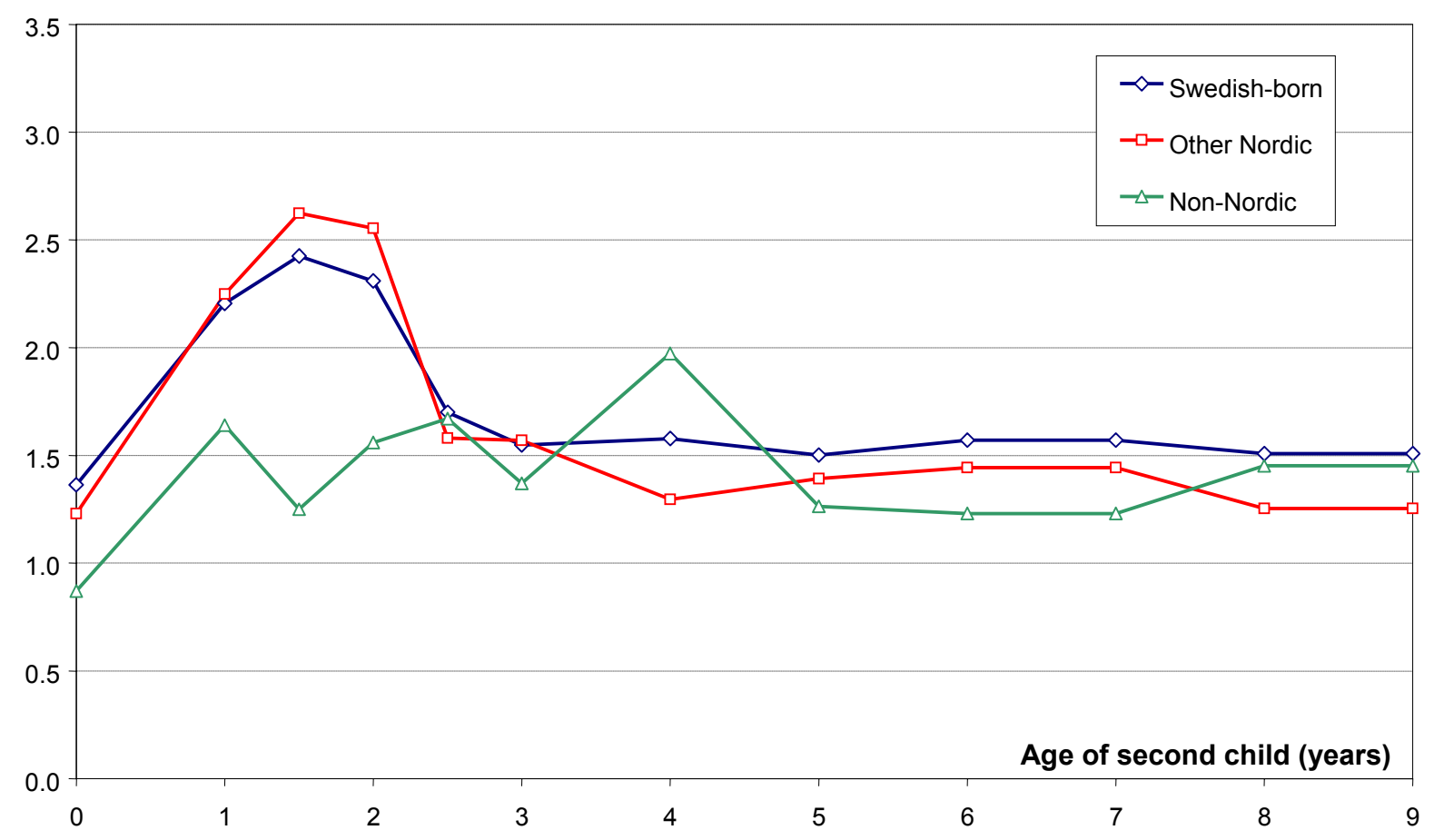


Figure 3: Second- and third-birth risks in 1990 relative to 1981, by duration since last previous birth. Swedish-born mothers, by educational level

a) Second-birth risks

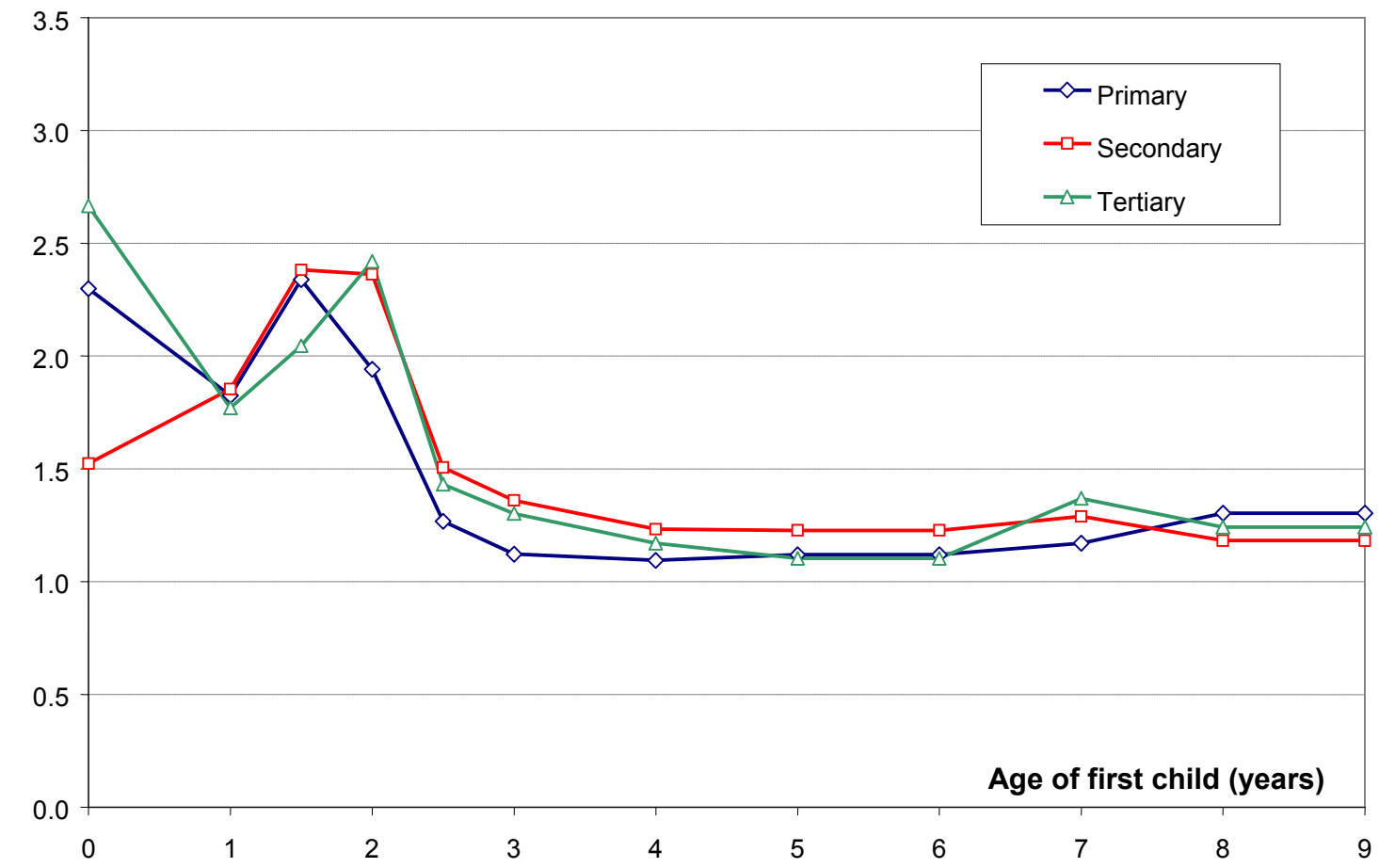

b) Third-birth risks

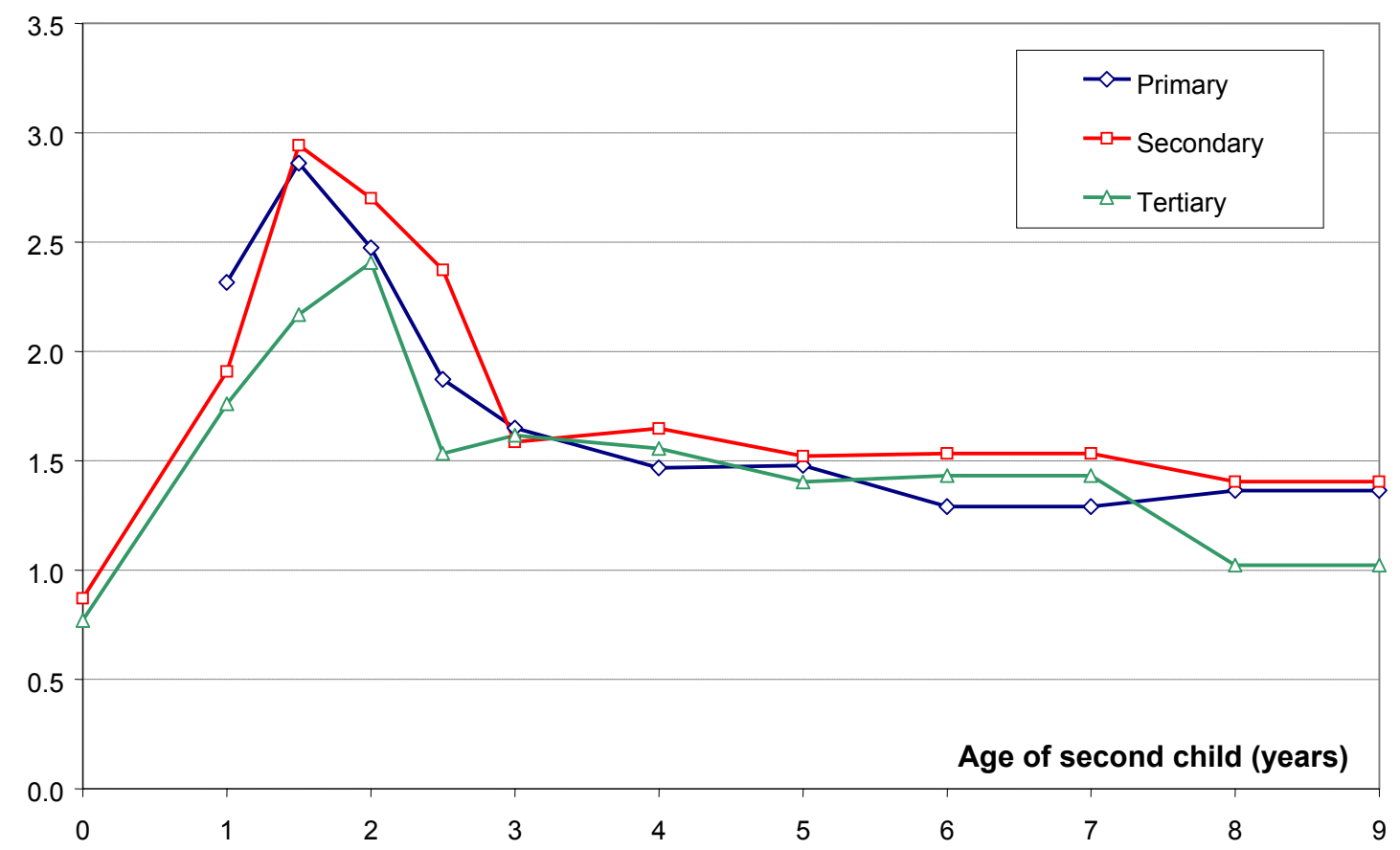


Figure 4: Second-birth risks relative to that in 1981, by calendar year. Swedish-born couples, by the educational levels of both parents simultaneously

a) Risks for mothers by their educational level and duration since first birth

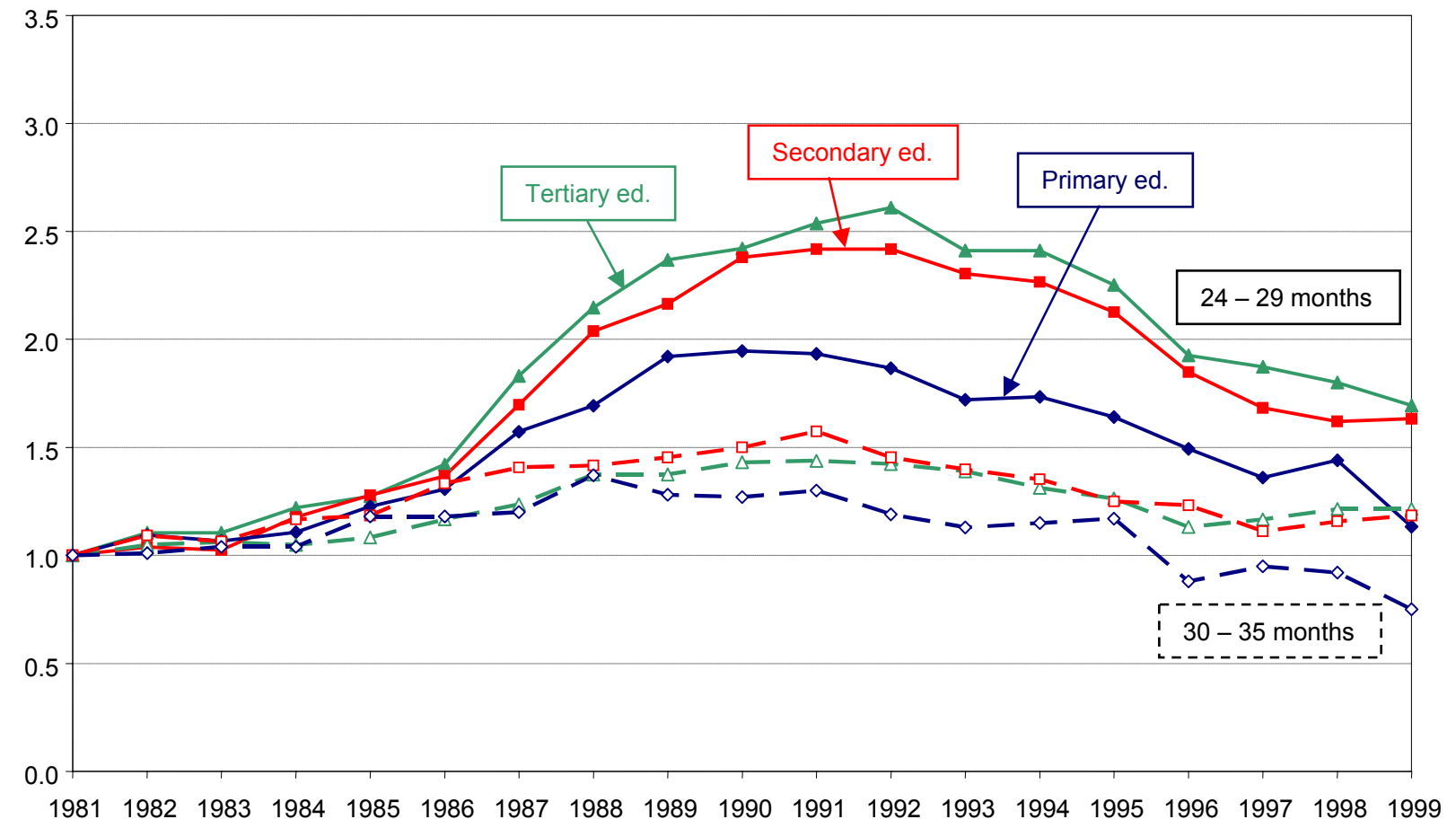

b) Risks for fathers by their educational level and duration since first birth

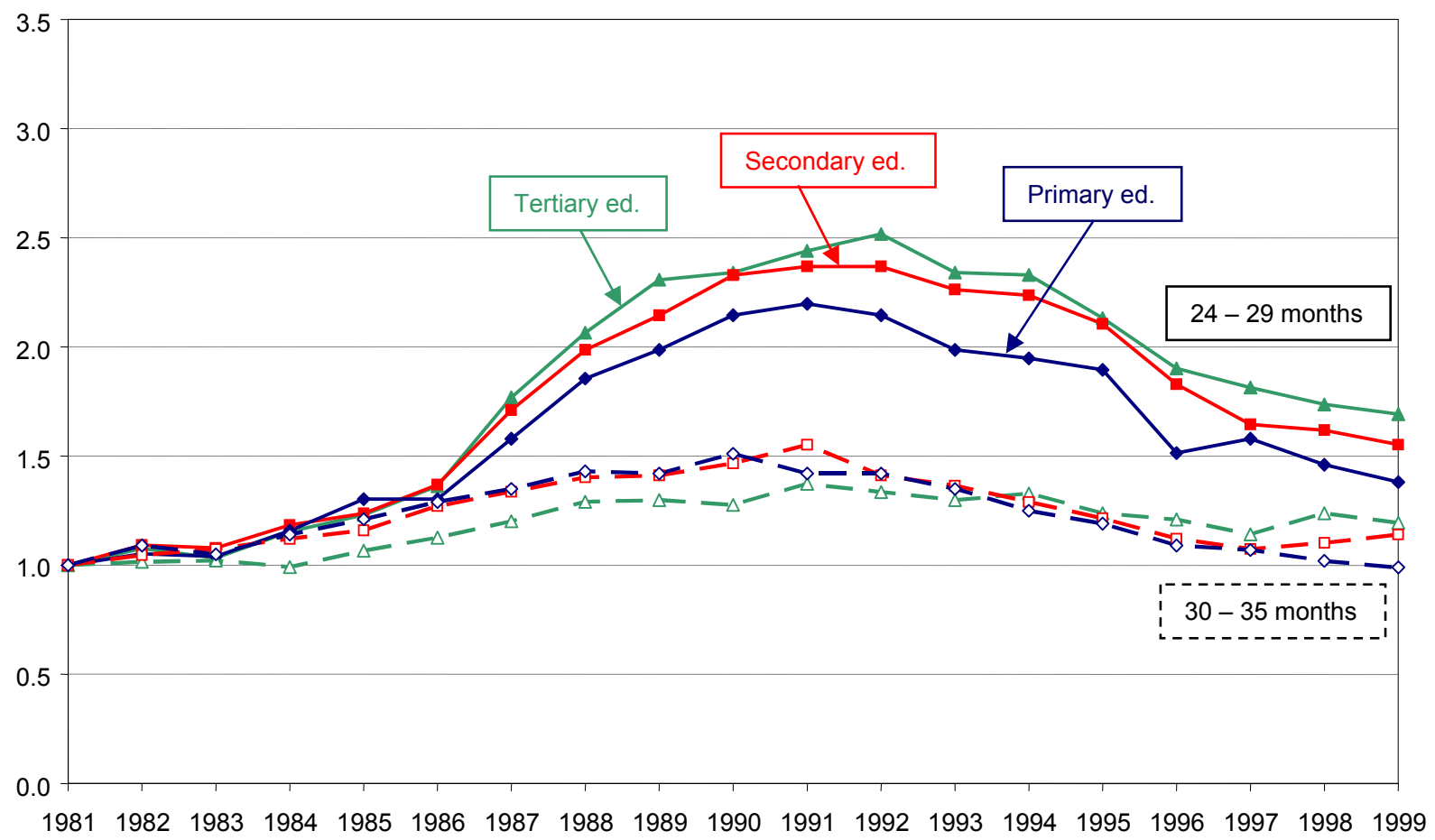

